\title{
CONSEQUENCE OF TWO PROTOCOLS AND ENERGY DOSES OF LOW-LEVEL LASER THERAPY ON THE RATE OF ORTHODONTIC CANINE RETRACTION: A PROSPECTIVE CLINICAL EVALUATION
}

\author{
Abdullah Mohammed Al-Haj ${ }^{*}$, Farouk Ahmed Hussein ${ }^{* *}$, \\ Mohamed Abd El-Rhman Shendy ${ }^{* * *}$ and Akram Abbas El-Awady ${ }^{* * * *}$
}

\begin{abstract}
Objective: This study aimed to determine whether orthodontically moved maxillary canines exposed to two different protocols and dosage of LLLT exhibited differences in amount and rate of tooth movement.

Materials and Methods: Fifteen patients, 12 females and 3males, with mean age of $17.48 \pm 2.95$ years were included. They had a clinical indication for bilateral extraction of first maxillary premolars. Using a split mouth design, maxillary left and right sides were randomly divided into two groups. In group 1, LLLT delivered at 10 points; 5 from buccal and 5 from palatal aspects with total dose of $8 \mathrm{~J} /$ session. In group II, laser applied from buccal side only at 5 points with dose of $4 \mathrm{~J}$ per session. In both protocols, gallium aluminum-arsenide diode laser applied in continuous mode with $635 \mathrm{~nm}, 100 \mathrm{~mW}, 25 \mathrm{~J} / \mathrm{cm}^{2}, 8$ seconds/ point, $0.8 \mathrm{~J} /$ point. Amount and rate of maxillary canine retraction and degree of anchorage loss were determined by intraoral and three-dimensional digital models measurements.
\end{abstract}

Results: Clinical and model evaluations demonstrated no significant difference $(\mathrm{p}<0.05)$ between both groups. After 24 weeks, total amounts of canine retraction were $6.86 \pm 1.60 \mathrm{~mm}$ and $6.65 \pm 1.59 \mathrm{~mm}$ in group I and group II, respectively. Moreover, anchorage loss displayed $-0.35 \mathrm{~mm}$ $\pm 0.18 \mathrm{~mm}$ in group I and $-0.44 \mathrm{~mm} \pm 0.24 \mathrm{~mm}$ in group II.

Conclusion: With the current settings, both protocols and energy doses of LLLT accomplished comparable amount and rate of maxillary canine retraction. Additionally, they displayed an equivalent minimal degree of anchorage loss.

KEY WORDS: Low-Level Laser Therapy, Orthodontic Tooth movement, Canine Retraction, Two Protocols and Energy Doses.

\footnotetext{
* Postgraduate MSc Student, Department of Orthodontics, Faculty of Dental Medicine (Boys), Al-Azhar University, Cairo, Egypt

** Associate Professor \& Acting Chairman, Department of Orthodontics, Faculty of Dental Medicine (Boys), Al-Azhar University, Cairo, Egypt.

*** Lecturer, Department of Orthodontics, Faculty of Dental Medicine (Boys), Al-Azhar University, Cairo, Egypt.

**** Professor, Department of Oral Medicine \& Diagnosis \& Radiology, Faculty of Dental Medicine (Boys), Al-Azhar University, Cairo, Egypt
} 


\section{INTRODUCTION}

Orthodontic therapy has its weight based on esthetic and functional rehabilitation of the masticatory system and this field has been greatly developed to achieve desired results both clinically and technically. However, the relatively long duration of orthodontic therapy is one of the most frequent complaints of orthodontic patients; particularly the adults. Conventional treatment with fixed appliances likely requires an average of 1.5 to 2 years which can be influenced by several factors such as case severity, extraction versus non extraction therapy, clinical expertise and patient cooperation. ${ }^{1}$ Additionally, distal canine movement is the core timeconsuming procedure for premolar extraction cases. Conventional techniques result in canine retraction rate of 0.5 to $1 \mathrm{~mm}$ per month, depending on the patient's age and sex and full canine retraction may require 5-9 months., ${ }^{2,3}$

Interestingly many researchers have used pharmaceutical approaches, to achieve efficient orthodontic tooth movement (OTM), via biochemical agents such as prostaglandin E2, 1, 25-dihydroxy vitamin D3, osteocalcin, relaxin, and parathyroid hormone. Moreover, other modalities have been used to accelerate OTM and have attracted considerable scientific interest such as pulsed electromagnetic field, electrical current, mechanical vibration, corticotomy, dento-alveolar distraction, periodontal ligament distraction, and laser therapy. ${ }^{2-5}$

The biostimulatory effects of laser irradiation on tissues are accompanied by no more than $1^{\circ} \mathrm{C}$ increase in local temperature. It was suggested that the laser lights from red to near-infrared regions functions by stimulating antenna pigments thus increasing the mitochondrial ATP production. This promotes greater protein synthesis, accelerates DNA duplication and RNA replication thus accelerating the cell metabolism. ${ }^{5,6}$ Currently, low level laser therapy (LLLT) has drawn attention as a non-invasive tool to accelerate OTM. ${ }^{5,7-15}$ However, other studies have shown no significant increase in the rate OTM subsequent to LLLT. ${ }^{16-20}$

One important and efficient issue for LLLT is to define the optimum dose or energy density for orthodontic treatment. Energy density is the amount of energy received by a target tissue that considered the most important factor for biostimulatory effects of LLLT. ${ }^{17,21,22}$ Nevertheless, there is much debate about this matter and additional clinical studies were recommended to identify the optimum energy density, wavelength, and duration of usage for LLLT. ${ }^{5,23,24}$ Accordingly the aim of the current study was to investigate whether two doses and protocols of LLLT could accelerate the rate of OTM in a group of patients undergoing orthodontic space closure.

\section{Specific objectives or hypotheses}

The primary purpose of this randomized clinical study was to assess the effect of two different protocols and doses of LLLT on the amount and rate of OTM during canine retraction for 6 months observation period. The secondary outcome was evaluation of anchorage loss in both protocols of LLLT before and after the 6-month. The null hypothesis was that there is no difference between both protocols of LLLT.

\section{PATIENTS AND METHODS}

\section{Study design, sample size estimate, eligibility cri- teria, and setting}

This study was a split-mouth randomized clinical trial with a 1:1 allocation. The methods were not changed after trial initiation. The study protocol was reviewed and approved by Institutional Review Board and the Ethical Research Committee of AlAzhar University, Cairo, Egypt (Approval number 201600001) and registered on ClinicalTrials.gov (ID: NCT04381442). 


\section{Study design and sample}

The current randomized clinical study was conducted on a total sample of 15 patients (12 females and 3 males) who ranged in age from 16 to 25 years with a mean age was $17.48 \pm 2.95$ years. They were selected from the outpatient clinic of the Department of Orthodontics, Faculty of Dental Medicine (Boys), Al-Azhar University, Cairo, Egypt. Participants were recruited after their recall from waiting lists in preparation for active orthodontic therapy from October 2016 to June 2017.

In accordance with previous clinical studies, ${ }^{7,10,18}$ sample size calculation was undertaken with $\mathrm{G}^{*}$ power statistical software (version 3.1) based on the following pre-established parameters: an $80 \%$ power, significance level (alpha) $=0.05$ (twotailed) taking into consideration a 1-mm mean difference with a standard deviation average of 0.2 $\mathrm{mm} /$ month in tooth movement that are clinically relevant. The estimated minimum sample needed to have adequate power to detect difference would be 10 patients. It was decided to increase the sample size to 15 patients in order to compensate for any possible drop-outs during the study period.

Patients were considered eligible for the study if they met the following inclusion criteria: both male and female subjects; complete permanent dentition ( $3^{\text {rd }}$ molars excluded); 16 or more years old, malocclusion that required extraction of at least maxillary first premolars, followed by canine retraction; and good oral hygiene and periodontal health.

The following exclusion criteria were applied: patients who diagnosed to have an indication for non-extraction approach, serious systemic diseases and/or long term medications that could interfere with OTM, previous orthodontic treatment, poor oral hygiene or periodontally compromised patients, and craniofacial anomalies or history of parafunctional habits. Subsequently; study objectives, purpose of intervention, and the associated risks and benefits were fully clarified to the patients and/ or legal guardians and signed informed consents were obtained before treatment initiation.

\section{Randomization and allocation concealment}

Using a split mouth design, left and right sides of the maxillary arch of each patient were randomly divided and allocated into two groups according to the protocol of application of low level laser therapy (LLLT) with a 1:1 allocation ratio as follows; group I where buccal and palatal LLLT protocol was applied, and group II where buccal LLLT protocol was used. The process of randomization and group allocation was undertaken via a computerized generated randomization plan using online software: http://www.randomlists.com/ list-randomizer. Identical materials and procedures were applied for both groups except for protocol of LLLT. One investigator generated the random allocation sequence and assigned the participants to each intervention.

\section{Interventions}

The diagnosis for each patient enrolled in the study was based on detailed clinical examination and routine orthodontic documentation and analysis of photographs (Fig.1), study models, cephalometric and panoramic radiographs.

\section{Orthodontic appliance}

All patients underwent conventional orthodontic treatment with fixed appliances. Direct bonded pre-adjusted metallic brackets utilizing 0.022in slot (3M Unitek ${ }^{\mathrm{TM}}$, California, USA) from right maxillary second premolar to left second maxillary premolar, except the maxillary first premolars, (canine bracket with hook) were bonded using light-cured orthodontic adhesive (Grengloo Two-Way Color Change Adhesive, Ormco Corp, Clendora, CA, USA). In addition, direct bonding single buccal molar tubes 0.022-in slot with hooks (American Orthodontics, USA) were bonded to 
the first maxillary molars (Fig. 2). A standardized bonding procedure was followed according to the manufacturer's instructions.

Atraumatic extraction of right and left maxillary first premolars was performed for all patients. After that, leveling and alignment were was initiated by utilizing 0.014-in Nickel Titanium (NiTi) arch wires followed by a standardized sequence of round and rectangular NiTi wires till reaching a final working rectangular 0.016×0.022-in stainless steel arch wire (American Orthodontics, Washington Avenue, USA). Maxillary canine retraction was initiated on the buccal aspect of both sides at the same time. The maxillary incisors were consolidated with 0.010 in steel ligature wires to prevent spaces to emerge among them during canine retraction (Fig. 2).

\section{Maxillary canine retraction}

In both groups, maxillary canine retraction was accomplished by a closed NiTi coil spring, 9 $\mathrm{mm}$ in length and 0.012 inch diameter (American Orthodontics, Washington Avenue, USA) that was attached directly from the mini-screw head to the buccal side of brackets' hook of both canines and secured with a stainless steel ligature wire. The coil spring was adjusted to deliver a constant force of 150 gram on the day of application ${ }^{7,8,10,13-15}$ by using a tension gauge (Correx gauge, Dentaurum, Germany) and activated every 28 days ${ }^{10,15,18}$ to ensure as possible constant and identical force in all patients and also between the two experimental groups at recall visits (Fig.2).

During maxillary canine retraction, anchorage was achieved through temporary anchorage devices. Bilateral mini-screws, $1.6 \mathrm{~mm} \times 8 \mathrm{~mm}$, (HUBIT Orthodontics, Korea) were inserted between the maxillary second premolar and maxillary first molar at the mucogingival junction of both buccal sides according to a standardized method (Fig.2). ${ }^{3,13}$ To minimize the intra-operator variations, all clinical procedures were performed by the same operator
(A.Y.E.). As occlusal interferences can decline the rate of tooth movement, therefore, during follow up intervals these were checked and if present, glass-ionomer cement (Ketac-Cem, ESPE DentalMedizin GmbH \& Co., Germany) was applied on mandibular molars to raise the bite.

\section{Low level laser therapy (LLLT)}

The maxillary canines in each group were exposed to LLLT through a gallium-aluminum-arsenide

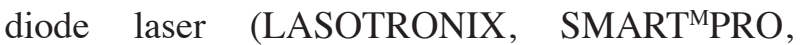
PIASECZNO, Poland) that was used at continuous mode (Fig. ). For bio-stimulation effects, the LLLT was used according to the following parameters (Table.1):

TABLE (1) Laser parameters used in the study

\begin{tabular}{|c|c|c|}
\hline Parameter & $\left(\begin{array}{c}\text { Group I } \\
\text { ( Buccal \&palatal } \\
\text { LLLT) }\end{array}\right.$ & $\begin{array}{c}\text { Group II } \\
\text { ( Buccal LLLT) }\end{array}$ \\
\hline Wavelength & $635 \mathrm{~nm}$ & $635 \mathrm{~nm}$ \\
\hline $\begin{array}{l}\text { Mode of application } \\
\text { (Emission type) }\end{array}$ & Continuous & Continuous \\
\hline Power output & $100 \mathrm{~mW}$ & $100 \mathrm{~mW}$ \\
\hline Energy density & $25 \mathrm{~J} / \mathrm{cm}^{2}$ & $25 \mathrm{~J} / \mathrm{cm}^{2}$ \\
\hline Exposure time/point & 8 seconds/ point & 8 seconds/ point \\
\hline Dose (Energy/point) & $\begin{array}{c}0.8 \mathrm{~J} / \text { point } \\
\text { (at } 10 \text { points) }\end{array}$ & $\begin{array}{l}0.8 \mathrm{~J} / \text { point } \\
\text { (at } 5 \text { points) }\end{array}$ \\
\hline Total dose / session & 8 Joule & 4 Joule \\
\hline Fiber optic tip diameter & $\begin{array}{c}2 \mathrm{~mm} \text {, in contact } \\
\text { method }\end{array}$ & $\begin{array}{c}2 \mathrm{~mm} \text {, in contact } \\
\text { method }\end{array}$ \\
\hline
\end{tabular}

In group I (one randomly-selected maxillary canine), the next protocol of LLLT was followed where 10 irradiations were performed at five points on the buccal side and five on the palatal one on the mucosa overlying the root at each time. To cover the entire periodontal fibers and alveolar process around the maxillay canines, distribution was as 
follows; two irradiation points on the cervical third (one medial and one distal), two on apical third (one medial and one distal) and one on middle third (on the center of the root). The laser device tip was applied perpendicular to the root and in direct contact with the mucosa from both buccal and palatal sides (Fig.3). ${ }^{7,8,10,13-19}$

In group II (contra-lateral maxillary canine), a total of 5 irradiations each time, were performed from the buccal side only ${ }^{12}$ and distributed in the same order around the maxillary canine as previously described (Fig.3B). From palatal side, the laser was held in the same way on the same points and for the same duration as the buccal side but the laser unit was not turned on (i.e. pseudo application of LLLT).
In both groups, the LLLT regimen was applied by the same operator as follows: immediately after mechanical activation for maxillary canine retraction (day 0), then; after 3 days, 7 days, 14 days, 21 days, and 28 days after the first activation. Subsequently, LLLT was applied on every $14^{\text {th }}$ day until achievement of 6 months observation period of canine retraction phase. ${ }^{10,18}$

All safety precautions where procedures were carried out in an isolated room and all precautions were followed before laser application where both patient and operator wore appropriate protective glasses provided by the manufacturer, specific for the used wavelength, in accordance with the standard safety rules (Fig.3A).

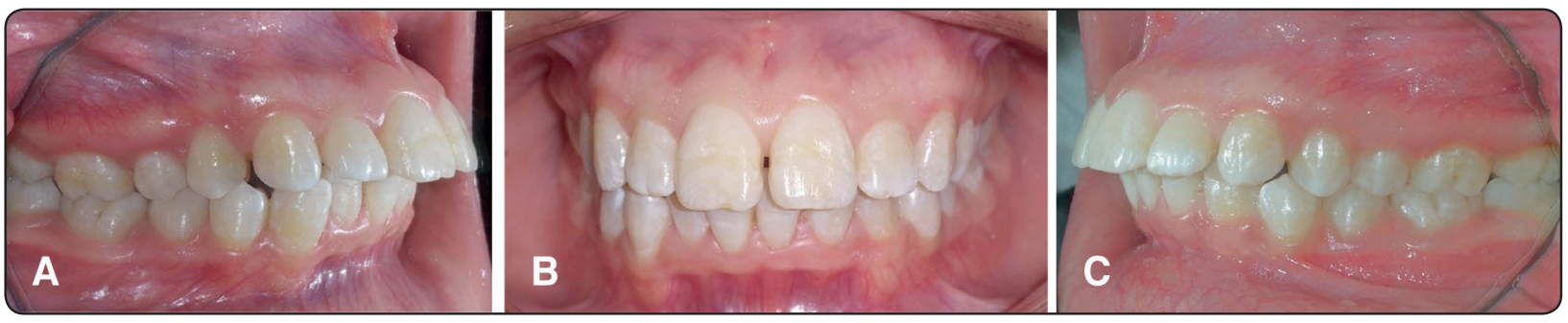

Fig. (1) Pre-treatment intra-oral photographs of a female patient presented for orthodontic treatment. A, Right side view, B. Frontal view, C. Left Side view.

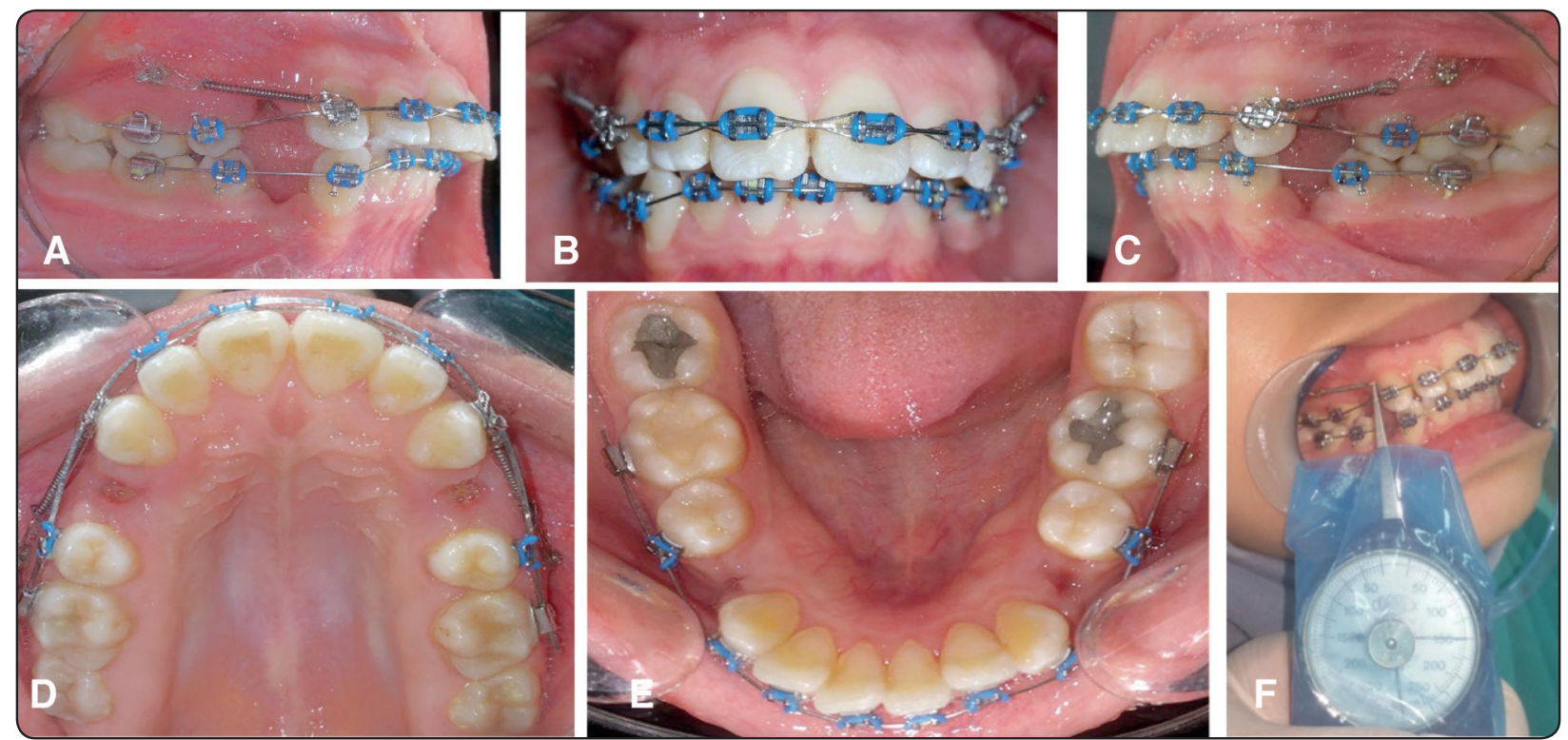

Fig. (2) Intraoral photographs showing fixed orthodontic appliance used in the present study and initiation of maxillary canine retraction on both sides (groups) via NiTi closed coil spring and mini-screws as temporary anchorage devise. F) Adjustment of retraction force with Correx tension gauge at every activation visit. 

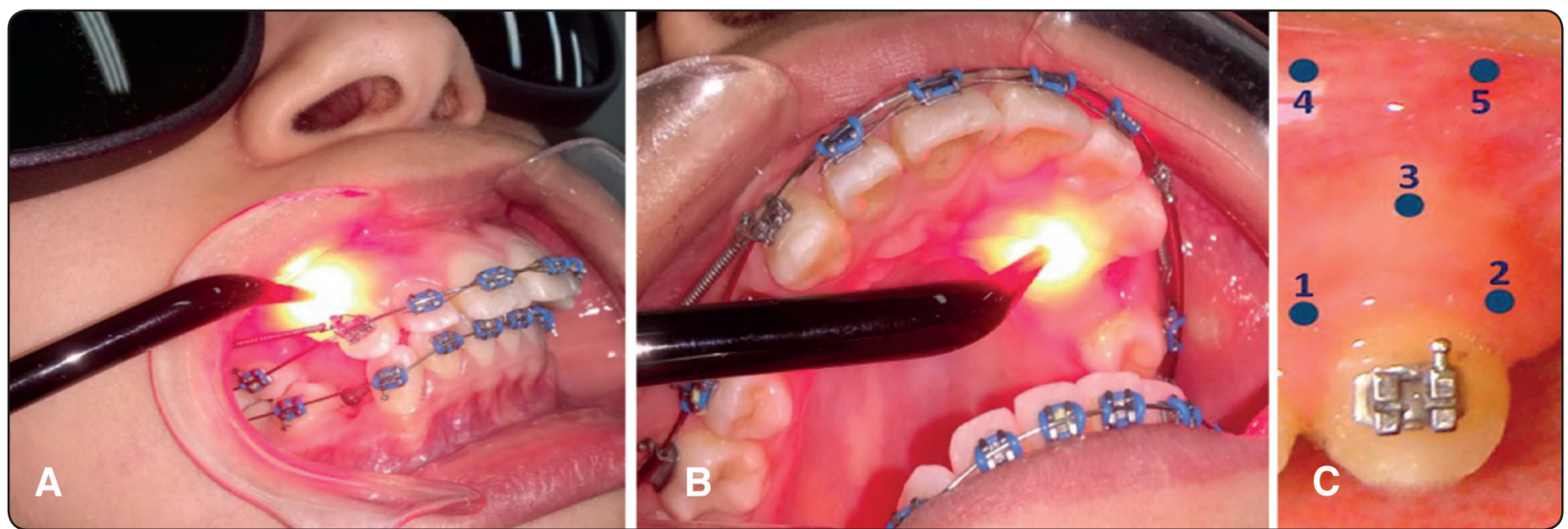

Fig. (3) Application of LLLT around the target tooth to be moved. (A) Buccal application for maxillary canine in both groups. (B) Palatal application in group I (C) Presentation of application's points. 1: Medial point on cervical third; 2: Distal point on cervical third; 3: On center of middle third; 4: Medial point on apical third; 5: Distal point on apical third.

\section{Study outcomes (measures)}

The primary outcome was evaluation and comparison of amount and monthly rate of distal movement of maxillary canine, in both groups, that were determined by direct intraoral measurements and indirect measurements of 3D scanned study models. The secondary outcome was evaluation and comparison of the amount of maxillary molar mesial movement (anchorage loss) between both groups via study models assessment. Blinding of operator was not possible, however, blinding was ensured at the measurement stage, in which other investigators (F.A.H. and M.A.S.) were blinded regarding the nature of the groups' allocation by coding of all pre- and post-retraction records. After that, all patients completed their comprehensive treatment and orthodontic objectives were achieved.

\section{Study measurements and data collection}

\section{Clinical measurements}

In both groups, the amount of maxillary canine retraction (extraction space closure) was measured as the distance $(\mathrm{mm})$ between reference points; tip of the mesiobuccal cusp of maxillary first permanent molar and tip of the maxillary canine cusp. ${ }^{7,19}$ This was recorded by a digital electronic caliper (Digimatic Caliper, Mitutoyo, China) to the nearest of $0.01 \mathrm{~mm}$ and all measurements were carried out twice, by the same investigator (F.A.H.) who had no knowledge about the nature of both sides and the groups' allocation, and the mean value was recorded.

Patients were evaluated immediately before first mechanical activation of maxillary canine retraction (T0), after 4 weeks (T1), after 8 weeks (T2), after 12 weeks (T3), after 16 weeks (T4), after 20 weeks (T5), and after 24 weeks (T6) of canine retraction (end of 6-month period of the study). The total amount of movement $(\mathrm{mm})$ was considered to be the difference between values $\mathrm{T} 0$ and $\mathrm{T} 6$. The rate of maxillary canine retraction (the change in extraction space size) was calculated as the amount of tooth movement divided by time of each observation interval i.e. $\mathrm{mm} / 4$ weeks. ${ }^{10}$

\section{Study models measurements}

The amount of maxillary canine distal movement and anchorage loss were evaluated on 3D digital study models that obtained in the same observation intervals as previously mentioned for clinical measurements. ${ }^{3,9,13-15,18}$ The 3D digital models prepared as follows; upper jaw impressions were taken with alginate (Cavex Ca37, Holland BV, Haarlem, 
Netherlands) at each observational appointment, and immediately poured to obtain dental casts. Subsequently, all models were scanned using a 3D laser scanner (AutoScan-Ex, Hangzhou Shining 3D Tech Co., Ltd, China). Afterward, scanned maxillary models were imported into Dolphin software (Dolphin Imaging, version 11.95.08.50 Premium, Chatsworth, Calif) where the software oriented models by placing them virtually in a mutual position to the baseline scanned one.

In all scanned images of dental casts, the third rugae area was used as a reference landmark as recommended in several studies 3,25 and $\mathrm{X}$ and Y-planes were used as reference planes of the coordinate system to ensure standardized orientation of all measurements from the occlusal view (Fig.4A)..$^{3,14,15}$ The midpalatal raphe line was used as Y-plane of coordinate system that defined by distinct points in anterior and posterior median parts of the palate. The X-plane was defined by the medial end of third rugae area on right and left sides. The origin of X-plane was located $30 \mathrm{~mm}$ posterior to the chosen rugae point and perpendicular to Y-plane. The most prominent point on the distal surface of maxillary canines as well as mesial contact point of maxillary first molars were also used as reference points to determine linear distances for both sides (Fig.4A). ${ }^{12-16}$ Seven 3D models were obtained for each patient and the measurement recorder (M.H.) was blinded about the allocation of study models to either group.

\section{Evaluation of amount of maxillary canine distal movement:}

In both groups, the amount of maxillary canine distal movement $(\mathrm{mm})$ was measured as distance from most prominent point on distal surface of the maxillary canines in baseline model (T0) to the X-plane. All succeeding 3D digital models (T1, T2, T3, T4, T5, and T6) were also measured with matching procedure (Fig.4B).,13,14 The total amount of movement was considered to be the difference between the values of T0 and T6 models. The amount of monthly movement was established by calculating the differences between sequential measurements (T0-T1, T1-T2, T2-T3, etc). The mean monthly movement was obtained by dividing the total amount of movement by 4 weeks. ${ }^{10}$

\section{Evaluation of amount of maxillary first molar mesial movement (Anchorage loss):}

In both groups (sides), the amount of maxillary first molar mesial movement was measured as the distance from the mesial contact point of the maxillary first molars in the baseline model (T0) and all subsequent models (T1, T2, T3, T4, T5, and T6) to the X-plane (Fig.4C). 4,18, 26
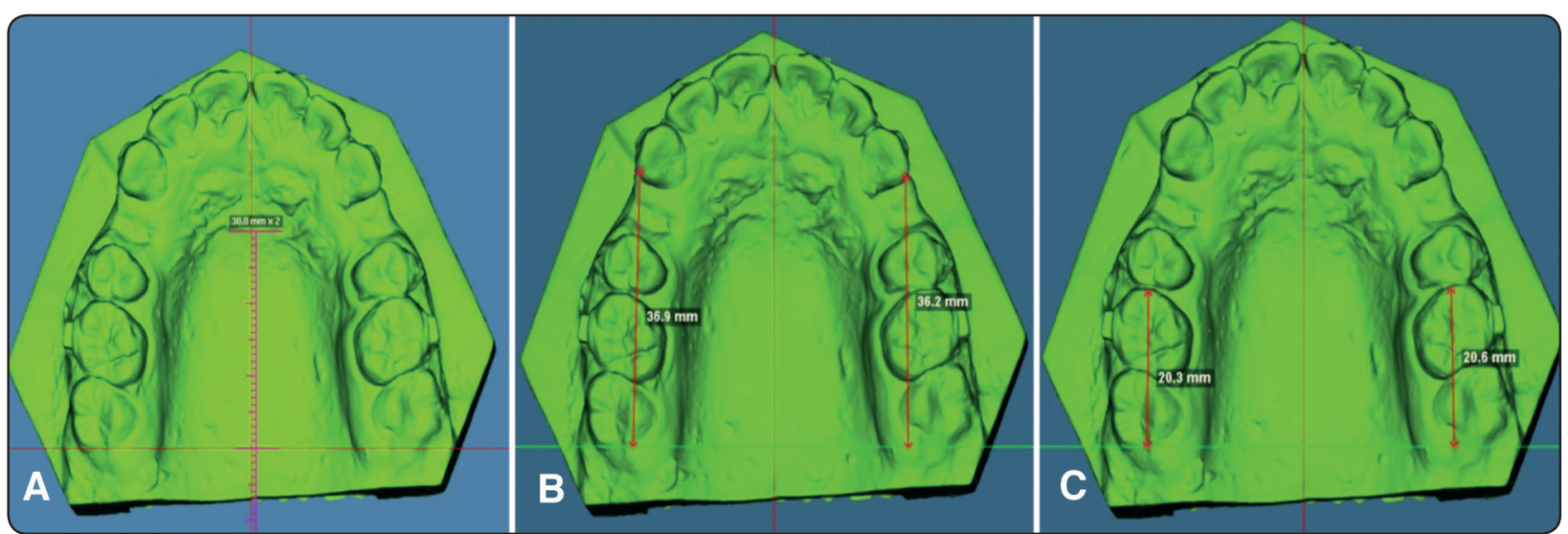

Fig. (4) Occlusal view of 3D digital scanned model (at T0) analyzed with Dolphin software showing: A. Reference points, X and Y reference planes used for linear assessment in both sides. B. Evaluation of maxillary canine distal movement. C. Evaluation of maxillary first molar mesial movement (Anchorage loss). 

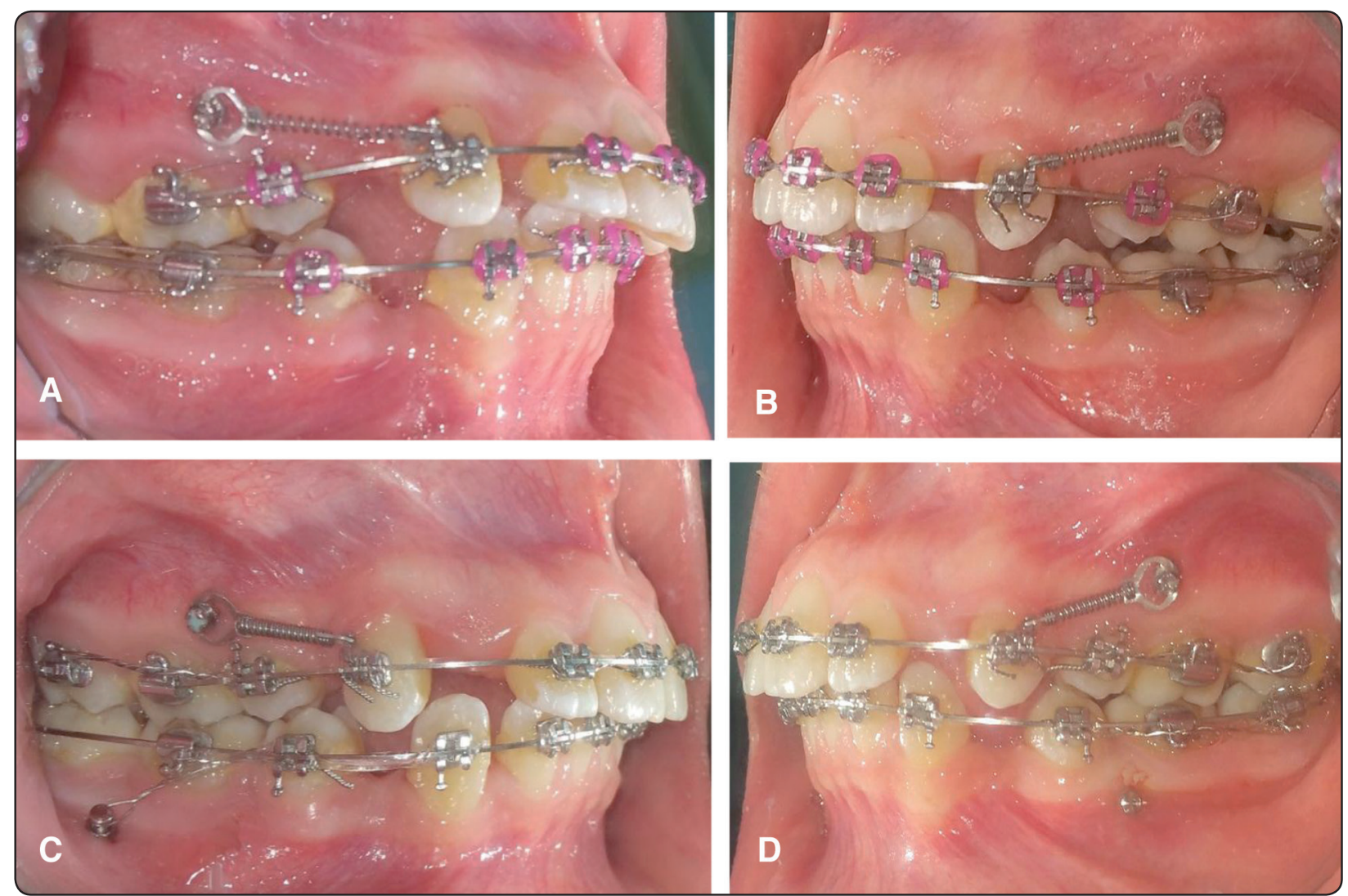

Fig. (5) Progress intraoral photographs showing maxillary canine retraction in both groups. A\&B: after 12 weeks (T3) interval, C\&D: after 24 weeks (T6) interval.

\section{Statistical analysis}

All data were collected and statistically analyzed by Statistical Package for Social Science software for Windows (SPSS, version 20, Inc., IBM Company, Chicago, III, USA). Quantitative variables were described by mean and standard deviation and descriptive statistics of mean differences, standard deviations, standard errors, and percentage of changes in all measurements were calculated for all variables in both groups.

Assessment of data distribution was performed using Kolmogorov-Smirnov test of normality for further choice of appropriate parametric and nonparametric tests. The results show that the data were normally distributed. Accordingly, parametric tests were used for statistical evaluation. Independent sample t-test was used for comparison of mean changes between both groups. Significance was determined at the 0.05 level of confidence with $95 \%$ confidence intervals.

\section{Error of the method (Reliability of measurements)}

For analysis of intra-observer reliability, paired t-test and Interclass Correlation Coefficient (ICC) were used. One examiner (who was blinded about the nature of study groups) repeated all measurements of $3 \mathrm{D}$ records for randomly selected six cases (30\% of the sample) for the mentioned variables within a 4-week interval. The reliability coefficient ranged from 0.975 to 0.988 , showing excellent measurement agreement. Moreover, paired sample t-test was conducted for the mean difference between the $1^{\text {st }}$ and the $2^{\text {nd }}$ measurements and no statistically significant difference ( $p>0.05)$ was found. 


\section{RESULTS}

\section{Participant flow, dropout, and losses}

The sample of this study started with 15 patients, 12 females and 3 males with a mean age was $17.48 \pm$ 2.95 years. Unfortunately, however, 3 patients ( 2 females and 1 male) were dropped out due to either missed appointments of laser application in 2 patients or failure to maintain a good oral hygiene in one patient. However, remaining 12 patients (10 females and 2 males) had successfully completed the full duration (6 months of canine retraction) of the study.

\section{Analysis of clinical measurements}

There are no statistically significant differences between both groups in any observation interval of study ( $p>0.05$ ). Table 2 shows comparison of mean amount $(\mathrm{mm})$ and percentage $(\%)$ changes in clinical measurements of maxillary canine retraction between both groups, at different observation intervals (per 4 weeks) with regard to pre-retraction value (T0), using independent sample t-test. Regarding combined buccal and palatal protocol with energy 8 $\mathrm{J} /$ session (group 1), rates and percentages of change achieved by the maxillary canine were $1.62 \pm 0.59$ $\mathrm{mm}(7.4 \%)$ in the $1^{\text {st }}$ month, $1.06 \pm 0.58 \mathrm{~mm}(4.8 \%)$ in $2^{\text {nd }}$ month, $1.1 \pm 0.47 \mathrm{~mm}(5.0 \%)$ in $3^{\text {rd }}$ month, $1.13 \pm 0.41 \mathrm{~mm}(5.2 \%)$ in $4^{\text {th }}$ month, $0.96 \pm 0.39$ $(4.4 \%) \mathrm{mm}$ in $5^{\text {th }}$ month, and $0.99 \pm 0.65(4.5 \%) \mathrm{mm}$ in $6^{\text {th }}$ month. Concerning buccal LLLT protocol with energy $4 \mathrm{~J} /$ session (group II), rate and percentage of change were as follows; $1.37 \pm 0.63 \mathrm{~mm}(6.3 \%)$ in $1^{\text {st }}$ month, $1.09 \pm 0.63 \mathrm{~mm}(5.0 \%)$ in $2^{\text {nd }}$ month, $0.93 \pm 0.55 \mathrm{~mm}(4.3 \%)$ in $3^{\text {rd }}$ month, $1.24 \pm 0.59 \mathrm{~mm}$ $(5.7 \%)$ in $4^{\text {th }}$ month, $1.1 \pm 0.46 \mathrm{~mm}(5.1 \%)$ in $5^{\text {th }}$ month, and $0.8 \pm 0.53 \mathrm{~mm}(3.7 \%)$ in $6^{\text {th }}$ month. There are no statistically significant differences $(p>0.05)$ between both groups throughout the study period.

\section{Analysis of 3D digital study models}

Table 3 shows comparison of amount ( $\mathrm{mm}$ ) and $\%$ of changes in 3D digital model measurements of maxillary canine distal movement between both groups using independent sample t-test at different intervals in relation to pre-retraction value (T0).

TABLE (2): Comparison of amount $(\mathrm{mm})$ and $\%$ of changes in clinical measurements of maxillary canine retraction between both groups using independent sample t- test.

\begin{tabular}{|c|c|c|c|c|c|c|c|c|c|}
\hline \multirow{2}{*}{ Interval } & \multicolumn{3}{|c|}{ Group I (N=12) } & \multicolumn{3}{c|}{ Group II(N=12) } & \multirow{2}{*}{ t-test } & \multirow{2}{*}{ p-value } & \multirow{2}{*}{ Sig. } \\
\cline { 2 - 9 } & Mean \pm SD & SE & \% of change & Mean \pm SD & SE & \% of change & & \\
\hline T0-T1 & $1.62 \pm 0.42$ & 0.17 & $7.4 \%$ & $1.36 \pm 0.35$ & 0.14 & $6.3 \%$ & 0.130 & 0.892 & NS \\
\hline T0-T2 & $2.68 \pm 0.70$ & 0.34 & $12.2 \%$ & $2.46 \pm 0.64$ & 0.31 & $11.4 \%$ & 0.078 & 0.938 & NS \\
\hline T0-T3 & $3.78 \pm 0.98$ & 0.18 & $17.3 \%$ & $3.38 \pm 0.88$ & 0.21 & $15.6 \%$ & 0.456 & 0.652 & NS \\
\hline T0-T4 & $4.84 \pm 1.15$ & 0.82 & $22.12 \%$ & $4.62 \pm 1.20$ & 0.71 & $21.3 \%$ & 0.954 & 0.439 & NS \\
\hline T0-T5 & $5.86 \pm 1.43$ & 0.93 & $26.78 \%$ & $5.71 \pm 1.42$ & 0.84 & $26.38 \%$ & 0.235 & 0.871 & NS \\
\hline T0-T6 & $6.86 \pm 1.60$ & 1.13 & $31.35 \%$ & $6.65 \pm 1.59$ & 1.12 & $30.73 \%$ & 0.294 & 0.772 & NS \\
\hline
\end{tabular}

Group I= Buccal and palatal LLLT protocol, Group II= Buccal LLLT protocol, $p=$ Probability level, $N S=$ Non significant $p>0.05, S D=$ Standard Deviation, $N=$ Number,$S E=$ Standard error, $T 0=$ Immediately before first mechanical activation of maxillary canine retraction, $T 1=$ after 4 weeks, $T 2=$ after 8 weeks, $T 3=$ after 12 weeks, $T 4=$ after 16 weeks, T5=after 20 weeks, $T 6=$ after 24 weeks, $m m=$ millimeter. Sig= Significance. 
There are no statistically significant differences ( $p>0.05)$ between both groups throughout all observation intervals of study. In combined buccal and palatal protocol with energy $8 \mathrm{~J} /$ secession (group 1), the rate and \% of change in maxillary canine distal movement were found to be $1.11 \pm 0.73$ $\mathrm{mm}(3.1 \%)$ in $1^{\text {st }}$ month, $0.59 \pm 0.59 \mathrm{~mm}(1.6 \%)$ in second month, $1.41 \pm 0.90 \mathrm{~mm}(3.9 \%)$ in $3^{\text {rd }}$ month, $1.04 \pm 0.83 \mathrm{~mm}(2.9 \%)$ in $4^{\text {th }}$ month, $1.02 \pm 1.62 \mathrm{~mm}$ $(2.8 \%)$ in $5^{\text {th }}$ month, and $0.48 \pm 1.01 \mathrm{~mm}(1.3 \%)$ in $6^{\text {th }}$ month.

Pertaining to the buccal protocol with energy $4 \mathrm{~J} /$ session (group II), rates and \% of change in canine movement was found to be $1.50 \pm 0.45 \mathrm{~mm}(4.2 \%)$ in $1^{\text {st }}$ month, $0.72 \pm 0.95 \mathrm{~mm}(2.0 \%)$ in $2^{\text {nd }}$ month, $1.43 \pm 1.42 \mathrm{~mm}(4.0 \%)$ in $3^{\text {rd }}$ month, $0.76 \pm 1.06$ $\mathrm{mm}(2.1 \%)$ in $4^{\text {th }}$ month, $0.61 \pm 0.82 \mathrm{~mm}(1.7 \%)$ in $5^{\text {th }}$ month, and $1.34 \pm 0.74 \mathrm{~mm}(3.8 \%)$ in $6^{\text {th }}$ month.
After 6 months, the total amount of distal movement achieved by maxillary canine was $5.66 \pm 1.47 \mathrm{~mm}$ $(15.8 \%)$ and $6.36 \pm 1.65 \mathrm{~mm}(17.8 \%)$ with regard to pre-retraction value; in group I and group II, respectively, with no statistically significant differences $(\mathrm{p}>0.05)$.

Table 4 shows comparison of amount ( $\mathrm{mm}$ ) and $\%$ of changes in 3D digital model measurements of maxillary $1^{\text {st }}$ molar mesial movement at different intervals (per 4 weeks) in relation to pre-retraction value (T0) between both groups using independent sample t-test. There are no statistically significant $(\mathrm{p}>0.05)$ differences between both groups throughout all observation intervals. The analysis displayed $-0.35 \mathrm{~mm} \pm 0.18 \mathrm{~mm}$ in combined buccal and palatal protocol (group I) and $-0.44 \mathrm{~mm} \pm 0.24$ $\mathrm{mm}$ in buccal one (group II) after 6 months with respect to pre-retraction values.

TABLE (3): Comparison of amount ( $\mathrm{mm}$ ) and \% of changes in 3D models measurements of maxillary canine retraction in relation to pre-retraction value between both groups using independent sample t-test.

\begin{tabular}{|c|c|c|c|c|c|c|c|c|c|c|c|}
\hline \multirow{2}{*}{ 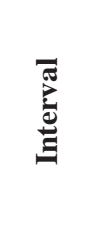 } & \multicolumn{2}{|c|}{$\begin{array}{l}\text { Group I } \\
(\mathrm{N}=12)\end{array}$} & \multicolumn{2}{|c|}{$\begin{array}{c}\text { 95\% Confidence } \\
\text { interval }\end{array}$} & \multicolumn{2}{|c|}{$\begin{array}{c}\text { Group II } \\
(\mathbf{N}=12)\end{array}$} & \multicolumn{2}{|c|}{$\begin{array}{c}\text { 95\% Confidence } \\
\text { interval }\end{array}$} & \multirow{2}{*}{ t-test } & \multirow{2}{*}{ p-value } & \multirow{2}{*}{ 氖 } \\
\hline & Mean \pm SD & $\begin{array}{c}\% \text { of } \\
\text { change }\end{array}$ & $\begin{array}{l}\text { Upper } \\
\text { bound }\end{array}$ & $\begin{array}{l}\text { Lower } \\
\text { bound }\end{array}$ & Mean \pm SD & $\begin{array}{c}\% \text { of } \\
\text { change }\end{array}$ & $\begin{array}{l}\text { Upper } \\
\text { bound }\end{array}$ & $\begin{array}{l}\text { Lower } \\
\text { bound }\end{array}$ & & & \\
\hline T0-T1 & $1.11 \pm 0.73$ & $3.1 \%$ & 1.52 & 0.65 & $1.50 \pm 0.45$ & $4.2 \%$ & 1.75 & 1.24 & 0.135 & 0.819 & NS \\
\hline T0-T2 & $1.70 \pm 0.44$ & $4.7 \%$ & 1.95 & 1.45 & $2.22 \pm 0.58$ & $6.2 \%$ & 2.55 & 1.89 & 0.261 & 0.861 & NS \\
\hline T0-T3 & $3.11 \pm 0.81$ & $8.7 \%$ & 3.57 & 2.65 & $3.65 \pm 0.95$ & $10.2 \%$ & 4.19 & 3.11 & 0.472 & 0.598 & NS \\
\hline T0-T4 & $4.16 \pm 1.08$ & $11.6 \%$ & 4.77 & 3.55 & $4.41 \pm 1.15$ & $12.3 \%$ & 5.06 & 3.76 & 0.447 & 0.403 & NS \\
\hline T0-T5 & $5.18 \pm 1.35$ & $14.4 \%$ & 5.94 & 4.42 & $5.02 \pm 1.31$ & $14.0 \%$ & 5.76 & 4.28 & 0.351 & 0.676 & NS \\
\hline T0-T6 & $5.66 \pm 1.47$ & $15.8 \%$ & 6.49 & 4.83 & $6.36 \pm 1.65$ & $17.8 \%$ & 7.29 & 5.43 & 0.347 & 0.678 & NS \\
\hline
\end{tabular}

Group $I=$ Buccal and palatal LLLT protocol, Group $I I=$ Buccal $L L L T$ protocol, $P=$ Probability level, NS= Non significant $P>0.05, S D=$ Standard Deviation, $N=$ Number, $T 0=$ immediately before first mechanical activation of maxillary canine retraction, T1 = after 4 weeks, T2= after 8 weeks, T3=after 12 weeks, T4=after 16 weeks, T5=after 20 weeks, T6=after 24 weeks, mm= millimeter. 
TABLE (4): Comparison of amount ( $\mathrm{mm}$ ) and $\%$ of changes in 3D model measurements of maxillary $1{ }^{\text {st }}$ molar mesial movement (anchorage loss) between both groups using independent sample t- test.

\begin{tabular}{|c|c|c|c|c|c|c|c|c|c|c|}
\hline \multirow{2}{*}{ 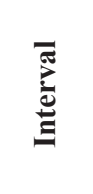 } & \multicolumn{2}{|l|}{ Group I } & \multicolumn{2}{|c|}{$\begin{array}{c}95 \% \text { Confidence } \\
\text { Interval }\end{array}$} & \multicolumn{2}{|l|}{ Group II } & \multicolumn{2}{|c|}{$\begin{array}{c}95 \% \text { Confidence } \\
\text { Interval }\end{array}$} & \multirow{2}{*}{ p-value } & \multirow{2}{*}{ 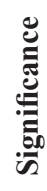 } \\
\hline & Mean \pm SD & $\begin{array}{c}\% \\
\text { of change }\end{array}$ & $\begin{array}{l}\text { Upper } \\
\text { bound }\end{array}$ & $\begin{array}{l}\text { Lower } \\
\text { bound }\end{array}$ & Mean \pm SD & $\begin{array}{c}\% \\
\text { of change }\end{array}$ & $\begin{array}{l}\text { Upper } \\
\text { bound }\end{array}$ & $\begin{array}{l}\text { Lower } \\
\text { bound }\end{array}$ & & \\
\hline T0-T1 & $-0.12 \pm 0.06$ & $-0.6 \%$ & -0.07 & -0.16 & $-0.17 \pm 0.07$ & $-0.9 \%$ & -0.12 & -0.21 & 0.81 & NS \\
\hline T0-T2 & $-0.27 \pm 0.32$ & $-1.30 \%$ & -0.04 & -0.48 & $-0.29 \pm 0.23$ & $-1.46 \%$ & -0.12 & -0.44 & 0.97 & NS \\
\hline T0-T3 & $-0.28 \pm 0.16$ & $-1.40 \%$ & -0.16 & -0.38 & $-0.30 \pm 0.14$ & $-1.53 \%$ & -0.20 & -0.39 & 0.97 & NS \\
\hline T0-T4 & $-0.29 \pm 0.13$ & $-1.44 \%$ & -0.19 & -0.37 & $-0.25 \pm 0.21$ & $-1.30 \%$ & -0.30 & -0.60 & 0.83 & NS \\
\hline T0-T5 & $-0.30 \pm 0.27$ & $-1.48 \%$ & -0.11 & -0.48 & $-0.32 \pm 0.41$ & $-1.16 \%$ & -0.33 & -0.90 & 0.71 & NS \\
\hline T0-T6 & $-0.35 \pm 0.18$ & $-1.21 \%$ & -0.23 & -0.47 & $-0.44 \pm 0.24$ & $-1.24 \%$ & -0.46 & -0.82 & 0.75 & NS \\
\hline
\end{tabular}

Group I= Buccal and palatal LLLT protocol, Group $I I=$ Buccal $L L L T$ protocol, $P=$ Probability level, NS=Non significant $P>0.05, S D=$ Standard Deviation, $N=$ Number,T0= Immediately before first mechanical activation of maxillary canine retraction, T1= after 4 weeks, T2=after 8 weeks, T3= after 12 weeks, T4= after 16 weeks, T5= after 20 weeks, T6=after 24 weeks, $m m=$ millimeter.

\section{DISCUSSION}

Although, LLLT seems to be a good choice for accelerating OTM, however, the literature revealed much debate about dosage for its biostimulatory effect. It was suggested that the effects of LLLT are based on Arndt-Schulz law where a small dose of any substance/ drug has a stimulating effect, whereas higher dose is inhibitory. ${ }^{22-24}$ Until now, there has been a lack of knowledge about the optimal dose for the stimulatory effects in human tissues. ${ }^{18,19}$ Hence, the current study aimed to investigate whether two different protocols and doses of LLLT could accelerate the rate of OTM in a group of patients undergoing orthodontic space closure.

In the current study, only the maxillary arch was evaluated in order to eradicate bias between the bone densities of the maxilla and mandible in accordance with several reports. The right and left sides were used as two groups (split mouth design), hence the same patient had matching interventions and acted as his/her own control, thus eliminating the inter-subject biological variability., ${ }^{7,86,18,19}$ Indeed, differences in tooth positions among individuals build inter-participant comparison an unreliable way to purely evaluate OTM. Nevertheless, two foremost challenges to the validity of split-mouth design were the possibilities of a systemic effect from LLLT and photoleakage to the contralateral side of dental arch. Yet, it was claimed that the greatest effects of laser were expected to be at the site of its administration. ${ }^{26}$

In this study, fixed orthodontic appliance and arch wires were standardized in all patients. In addition, we used a uniform magnitude of force (150 g) via NiTi closed coil spring for maxillary canine retraction in accordance with several researchers that adjusted to the appropriate force using stress and tension gauge according to a consistent protocol for all patients. ${ }^{7,8,10}$ This was undertaken (every 28 days) to ensure as possible regular and equal force in all subjects and also between two investigational sides at recall visits. ${ }^{15,16,18}$ Blinding of both patients and operator was not possible. However, assessors of different measurements of study were completely blinded about the nature of evaluated groups. 
In this investigation, assessment of changes in amount and rate of canine retraction at more frequent intervals would facilitate a better understanding of temporal changes during closure of extraction spaces and time-dependence effects of LLLT. This extension of number of visits, although challenging from clinical management standpoint, would present insights as to whether LLLT is beneficial during orthodontic treatment. ${ }^{18}$ An ideal schedule for LLLI has not been established; however, it has been reported that application should be at the beginning of OTM. It was stated that distribution of LLLT energy into several points surrounding canine teeth could be more adequate due to a more homogeneous distribution..$^{7,10,14,18}$

\section{Clinical evaluation of amount and rate of canine retraction (extraction space size):}

The null hypothesis was accepted about the effects of LLLT on the rate of OTM. For both groups, in general, the present results showed that amount of extraction space was smaller at each subsequent interval, indicating that the extraction space was closing as anticipated in both groups. No noteworthy difference was noted in amount and rate of canine retraction between both protocols and doses of laser in all observation intervals. Likewise, Cruz et al ${ }^{7}$ and Kansal et al ${ }^{19}$ evaluated amount of canine retraction with an analogous direct clinical measurement with a digital caliper whereas others used matching measurements for estimation of canine retraction but via progress study models..$^{8,10,12}$

Regarding combined buccal and palatal protocol with energy $8 \mathrm{~J} /$ session (group 1), the highest rate of retraction was observed during $1^{\text {st }}$ month, while the lowest rate was in last 2 months of the study. For buccal LLLT protocol with energy $4 \mathrm{~J} / \mathrm{session}$ (group II), the peak of canine retraction was at $1^{\text {st }}$ month, whereas the lowest rate was in $6^{\text {th }}$ month. Both groups exhibited comparable average rates of OTM and percentage of changes in all observation intervals. Moreover, at the end of 6-month observation period, total amount and rate of canine retraction was not much divergent.
Based on these findings, for possible biostimulatory effect, LLLT could be only applied from the buccal aspect during orthodontic canine retraction. Unfortunately, however, direct comparison of the existing results with previous clinical studies was limited because no previous researchers have compared the current protocols of LLLT. However, it is important to note that OTM's rates in our study were comparable to other studies lying on the effect of LLLT applied via combined buccal and palatal protocol..$^{7-10}$

\section{Measurements of amount and rate of canine dis- tal movement on scanned 3D models:}

Since clinical assessment of OTM does not take into consideration the amount of anchorage loss, therefore, 3D digital study models were added to analyze distance moved by maxillary canine away from any other possible tooth movement. In the current study, 3D scanned progress models were used as this technique allows a better visualization and precision to determine target points. ${ }^{27,28}$ Qamruddin et al, ${ }^{14}$ Uretürk et al, ${ }^{13}$ Sousa et al, ${ }^{9}$ and Alkebsi et $\mathrm{al},{ }^{3}$ used an equivalent method for measurements of canine distal movement that analyzed with a software analogous to the present study. Similarly, Varella et al ${ }^{15}$ Limpanichkul et al, ${ }^{16}$ and Heravi et al ${ }^{18}$ analyzed progress models in relation to the rugae area.

Parallel to clinical assessment, the current 3D model measurements revealed no considerable variation in amount and rate of canine distal movement between both protocols and doses of LLLT in all observation intervals of study. The existing deceleration of OTM in each group could be explained by 2 reasons. The first could be due to the nature of tooth movement during canine retraction. ${ }^{19}$ The second reason could be the decrease in frequency of laser application after $1^{\text {st }}$ month. ${ }^{22}$ Sousa et al ${ }^{9}$ and Doshi-Mehta and Bahd-Patil ${ }^{10}$ explained the decrease in rate of canine retraction on the basis of less frequent laser application after $1^{\text {st }}$ month. However, it is important to note that these 
clinical reports had fairly shorter observation period than the current study. As Cruz et al ${ }^{7}$ and Altan et al ${ }^{17}$ have declared the acute effect of LLLT may be another explanation of the lack of difference in rate of OTM in this study. They suggested that LLLT has a positive effect in the early phases of tooth movement. Likewise, on cellular level,

An important aspect to be mentioned, that most of studies that observed an acceleration of canine retraction were subject to errors due to possible mesial movement maxillary first molars (anchorage loss) associated with OTM that was not considered. This makes their conclusions are essentially pertaining to the rate of extraction space closure. To reduce this error in the present study, and in line with others, ${ }^{13-15}$ anchorage losses were calculated on 3D progress models which give a somewhat true explanation about actual amount and rate of maxillary canine retraction. In the current study, anchorage was obtained from mini-screws to evade any effect on measurements and few authors ${ }^{13}$ used such approach concerning LLLT and canine retraction.

Presently, analysis of anchorage loss displayed no sizeable differences between both groups throughout all observation intervals. Nevertheless, direct estimation of anchorage loss of both protocols was not reported in almost all studies that investigated the effect of LLLT on rate of canine retraction and so comparison with the present data was not possible. Even if these results are not statistically significant, however, it could be demonstrated that the current method was effective for canine retraction with negligible amounts of anchorage loss in all patients enrolled in the study.

Interestingly, the current findings are in line with several studies that applied a similar buccal and palatal protocol of group I and demonstrated no significant difference in OTM in laser-irradiated groups although compared to a placebo application. The present results are in harmony with those of Kansal et al ${ }^{19}$ although they used lower energy density of $4.2 \mathrm{~J} / \mathrm{cm}^{2}$ and measured the clinical canine movement for shorter period of 63 days. Limpanichkul et al ${ }^{16}$ also reported comparable results despite the fact that they used higher total

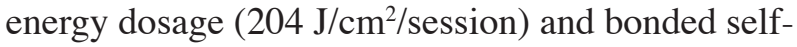
ligating brackets on maxillary canines. The results of Altan et al ${ }^{17}$ and Heravi et al ${ }^{18}$ also concur with current finding that buccal and palatal protocol had no stimulatory effect for canine movement.

In contrast, the results of Monea et al ${ }^{12}$ do not coincide with the present findings that might be due to using elastic chain for canine retraction with no information about its force value and degradation. Moreover, they assessed canine movement only for 10 days with different method and did not judge the anchorage loss. In addition, a number of studies utilized a buccal and palatal LLLT protocol matching to the present one and demonstrated dissimilar findings of significant acceleration of maxillary canine retraction compared to a placebo application. Ureturk et al ${ }^{13}$ reported significant increase of $40 \%$ in amount and rate of OTM after 90 days. However, they utilized much lower energy density of $5 \mathrm{~J} / \mathrm{cm}^{2}$ than the present one. Moreover, Cruz et $\mathrm{al}^{7}$ reported greater rate of extraction space closure. Conversely, they used lower energy density of $5 \mathrm{~J} / \mathrm{cm}^{2}$ for only 60 days and they did not declare anchorage loss that might affect their clinical measurements of OTM.

Besides, Doshi-Mehta and Bahd-Patil, ${ }^{10}$ Varella et al, ${ }^{15}$ and Sousa et al ${ }^{9}$ reported considerable acceleration of OTM with an equivalent protocol of current group 1, but they applied lower energy density. Furthermore, Youssef et $\mathrm{al}^{8}$ found divergent difference in rate of space closure that might be due to different retraction with frictionless mechanics by prefabricated Ricketts spring and lower energy density of $8 \mathrm{~J} / \mathrm{cm}^{2}$. Also, they did not mention anchorage loss that might affect their data. Too, Qamruddin et al ${ }^{14}$ reported greater rate of canine retraction after 9 weeks that might be also due to lower energy density of $7.5 \mathrm{~J} / \mathrm{cm}^{2}$ and the use of self-ligating brackets. 
In this study, both groups of protocols and doses of LLLT utilized wavelength of $635 \mathrm{~nm}$ that yielded no significant difference in the amount and rate of maxillary canine retraction. This could be due to this wavelength was too low and have less penetration depth that disallowed its penetration through the thickness of palatal alveolar bone. However, it was recommended that the current wavelength falls in the optimal range $(600-1000 \mathrm{~nm})$, providing a proper biostimulation effect because it has a low absorbance coefficient in chromophores (i.e., hemoglobin) and water that allows for proper penetration of the laser beam into the tissues. ${ }^{24}$ Yet, the current protocols displayed no noteworthy acceleration of OTM although $635 \mathrm{~nm}$ wavelength falls in the suggested optimal range.

It is not clear what the effective wavelength of LLLT is for OTM. Indeed, several studies have used varying values of wavelength to determine the effect of LLLT on OTM and have shown conflicting findings. ${ }^{5,23}$ Even so, Heravi et al ${ }^{18}$ used higher wavelength $810 \mathrm{~nm}$, with similar buccal and palatal protocol and failed to observe any significant effect concerning canine retraction. Correspondingly, Kansal et al, ${ }^{19}$ Limpanichkul et al, ${ }^{16}$ and Altan et al 17 applied higher wavelengths of $904 \mathrm{~nm}, 860 \mathrm{~nm}$, $820 \mathrm{~nm}$, respectively, and reported no significant acceleration of OTM between laser-irradiated and placebo sides. On the contrary, other authors used relatively higher wavelengths and recognized positive effects for OTM.7-10,13-15 This inconsistency warrant further clinical evaluation concerning the appropriate wavelength of LLLT for acceleration of OTM. One more reason for controversial results could be attributed to variations in biology, bone characteristics, position of the canine root in cortical plates. ${ }^{19}$

One limitation of the current study was the absence of a control group without LLLT which would help to analyze effectiveness of both protocols. Assessment of dissimilar laser's parameters, frequency, and interval between irradiations are required to identify the best biostimulatory dose of LLLT and to identify an optimum laser protocol to maximize the desired effect. This will aid the orthodontic specialty in its persistent seek for non-invasive ways to reduce treatment time and diminish detrimental side effects of extended orthodontic therapy.

Nevertheless, the clinical usefulness of both protocols of LLLT must be considered in combination with the number of patient's follow-up visits, total treatment duration, and cost of treatment that could not justify the benefits to many patients in terms of decreased treatment time.

\section{CONCLUSION}

With the current parameters of LLLT, the following conclusions could be extracted:

1. Buccal or buccal and palatal protocols of application with energy doses ( $4 \mathrm{~J}$ or $8 \mathrm{~J} /$ session, respectively), accomplished comparable amount and rate of maxillary canine retraction.

2. Additionally, both protocols displayed an equivalent minimal degree of anchorage loss during canine retraction that is hard to be attributed to laser application.

3. For possible biostimulatory effect during canine retraction, LLLT could be applied just from the buccal aspect.

\section{REFERENCES}

1. Fisher MA, Wenger RM, Hans MG. Pretreatment characteristics associated with orthodontic treatment duration. Am J Orthod Dentofacial Orthop 2010;137:178-86.

2. Aboul-Ela SM, El-Beialy AR, El-Sayed KM, Selim EM, El-Mangoury NH, Mostafa YA. Miniscrew implant-supported maxillary canine retraction with and without corticotomy-facilitated orthodontics. Am J Orthod Dentofacial Orthop 2011;139:252-59.

3. Alkebsi A, Al-Maaitah E, Al-Shorman H, Alhaija EA. Three-dimensional assessment of the effect of microosteoperforations on the rate of tooth movement during canine retraction in adults with Class II malocclusion: A randomized controlled clinical trial. Am J Orthod Dentofacial Orthop 2018;153:771-85.

4. Long H, Pyakurel U, Wang Y, Liao L, Zhou Y, Lai W. Interventions for accelerating orthodontic tooth movement: a systematic review. Angle Orthod 2013; 83:164-71. 
5. Carvalho-Lobato P, Garcia V, Kasem K, Ustrell-Torrent J, Tallon-Walton V, Manzanares-Cespedes MC. Tooth movement in orthodontic treatment with low-level laser therapy: A systematic review of human and animal studies. Photomed Laser Surg 2014;32:302-9.

6. Dominguez A, Castro P, Morales M. Cellular effects related to the clinical uses of laser in orthodontics. J Oral Laser Appl 2009;9:199-203.

7. Cruz DR, Kohara EK, Ribeiro MS, Wetter NU. Effects of low-intensity laser therapy on the orthodontic movement velocity of human teeth: a preliminary study. Lasers Surg Med 2004;35:117-20.

8. Youssef M, Ashkar S, Hamade E, Gutknecht N, Lampert F, Mir M. The effect of low-level laser therapy during orthodontic movement: a preliminary study. Lasers Med Sci 2008;23:27-33.

9. Sousa MV, Scanavini MA, Sannomiya EK, Velasco LG, Angelieri F. Influence of low-level laser on the speed of orthodontic movement. Photomed Laser Surg 2011; 29:191-96.

10. Doshi-Mehta G, Bhad-Patil WA. Efficacy of low-intensity laser therapy in reducing treatment time and orthodontic pain: a clinical investigation. Am J Orthod Dentofacial Orthop 2012;141:289-97.

11. Fujita S, Yamaguchi M, Utsunomiya T, Yamamoto H, Kasai K. Low-energy laser stimulates tooth movement velocity via expression of RANK and RANKL. Orthod Craniofac Res 2008;11:143-55.

12. Monea A, Monea M, Pop D, Beresescu G. The effect of low level laser therapy on orthodontic tooth movement. Optoelecron Adv Mat - Rapid Commun 2015:9:286-89.

13. Ureturk SE, Saraç M, Fıratlı S, Can ŞB, Güven Y, Firatlı E. The effect of low-level laser therapy on tooth movement during canine distalization. Lasers Med Sci 2017;32: 757-64.

14. Qamruddin I, Alam MK, Mahroof V, Fida M, Khamis MF, Husein A. Effects of low-level laser irradiation on the rate of orthodontic tooth movement and associated pain with self-ligating brackets. Am J Orthod Dentofacial Orthop 2017;152:622-30.

15. Varella AM, Ameet V. Revankar AVPatil AK. Low-level laser therapy increases interleukin-1b in gingival crevicular fluid and enhances the rate of orthodontic tooth movement. Am J Orthod Dentofacial Orthop 2018;154:535-44.

16. Limpanichkul W, Godfrey K, Srisuk N, Rattanayatikul C. Effects of low-level laser therapy on the rate of orthodontic tooth movement. Orthod Craniofac Res 2006;9:38-43.

17. Altan BA, Sokucu O, Toker H, Sumer Z. The effects of low-level laser therapy on orthodontic tooth movement: Metrical and immunological investigation. JSM Dent 2014; 2 : 1040-45.

18. Heravi F, Moradi A, Ahrari F. The effect of low level laser therapy on the rate of tooth movement and pain perception during canine retraction. Oral Health Dent Manag 2014;13:183-88.

19. Kansal A, Kittur N, Kumbhojkar V, Keluskar KM, Dahiya P. Effects of low-intensity laser therapy on the rate of orthodontic tooth movement: A clinical trial. Dent Res J 2014;11:481-88.

20. Marquezan M, Bolognese AM, Araujo MT. Effects of two low-intensity laser therapy protocols on experimental tooth movement. Photomed Las Surg 2010;28:757-62.

21. Cossetin E, Janson G, de Carvalho MGF, de Carvalho RA, Henriques JFC, Garib D. Influence of low-level laser on bone remodeling during induced tooth movements in rats. Angle Orthod 2013;83:1015-21.

22. Huang YY, Chen AC, Carroll JD, Hamblin MR. Biphasic dose response in low level light therapy. Dose Response 2009;7:358-83.

23. Sousa MV, Pinzan A, Consolaro A, Henriques JF, de Freitas MR. Systematic literature review: influence of lowlevel laser on orthodontic movement and pain control in humans. Photomed Laser Surg 2014;32:592-99.

24. Ge MK, He WL, Chen J, Wen C, Yin X, Hu ZA, et al. Efficacy of low-level laser therapy for accelerating tooth movement during orthodontic treatment: A systematic review and meta-analysis. Lasers Med Sci 2015;30: 1609-18.

25. Hoggan BR, Sadowsky C. The use of palatal rugae for the assessment of anteroposterior tooth movements. Am J Orthod Dentofacial Orthop 2001;119:482-88.

26. Chung H, Dai T, Sharma SK, Huang YY, Carroll JD, Hamblin MR. The nuts and bolts of low-level laser (light) therapy. Annals Biomed Engin 2012;40:516-33.

27. Sousa MV, Vasconcelos EC, Janson G, Garib D, Pinzan A. Accuracy and reproducibility of 3-dimensional digital model measurements. Am J Orthod Dentofacial Orthop 2012;142:269-73.

28. Fleming P, Marinho V, Johal A. Orthodontic measurements on digital study models compared with plaster models: a systematic review. Orthod Craniofac Res 2011;14:1-16. 